\title{
An Exploration of Electrospun Fibers Containing Drug-Cyclodextrin Inclusion Complexes
}

\author{
Fatimah $^{1}$, Zeynep Aytac ${ }^{1,2}$, Tamer Uyar ${ }^{2,3}$, George Pasparakis ${ }^{1}$, Gareth R. Williams ${ }^{1}$ \\ ${ }^{1}$ UCL School of Pharmacy, 29-39 Brunswick Square, London WC1N 1AX, United Kingdom \\ ${ }^{2}$ Institute of Materials Science \& Nanotechnology, Bilkent University, Ankara, 06800, Turkey \\ ${ }^{3}$ Department of Fiber Science and Apparel Design, College of Human Ecology, Cornell University, Ithaca, NY, 14853, USA
}

\begin{abstract}
A series of new core-shell fibers were developed containing anticancer drugs (5-fluorouracil or ferulic acid) and their cyclodextrin inclusion complexes, with a gadolinium-based magnetic resonance imaging (MRI) contrast agent. These were prepared by electrospinning, a simple method for producing ultra-fine fibers through the application of a strong electrostatic force on a polymer solution. The shell of the fibers was formed from Eudragit S100, and the drugs were loaded in the core. Scanning electron microscopy images showed the formation of smooth ribbon-like fibers, with diameters ranging from 1.4 to $5.1 \mu \mathrm{m}$, and transmission electron microscopy reveals a transparent interface between the core and shell compartments. X-ray diffraction and differential scanning calorimetry data confirmed the encapsulation of the drug into the cyclodextrin cavity and the formation of amorphous solid dispersions in the fibers. Drug release from the systems at $\mathrm{pH} 1$ and 7 showed that all the drug loading was released within one hour at $\mathrm{pH} 1$. Based on these results, it is proposed that the relatively low molecular weight drugs were able to diffuse out of the system into the release medium at acidic $\mathrm{pH}$, despite the insolubility of the shell polymer under these conditions. These findings have important implications for the design of electrospun drug delivery systems.
\end{abstract}

Keywords: Electrospinning, Polymer fibers, Anticancer, Cyclodextrin, Inclusion Complex, Eudragit S100

*Corresponding author

Email: Fatimah.14@ucl.ac.uk

\section{INTRODUCTION}

Electrospinning is a straightforward process for producing ultra-fine fibers with diameters typically on the nanometer to micrometer scale through the application of a strong electrostatic force on a polymer solution or melt (Hu et al., 2014). It is a widespread technique for the fabrication of nanofibers because of its simplicity, versatility, cost-effectiveness, the possibility for scaleup, and the ability to use a broad range of polymers (Zamani et al., 2013). High drug loadings and controlled drug release profiles at the site of interest can be elicited (Hu et al., 2014).

Electrospinning involves the application of a high electric potential $(\mathrm{kV})$ to the tip of a spinneret through which a polymer solution is fed. When the potential reaches a critical voltage, the polymer droplet at the end of the syringe will deform into a conical shape (the Taylor cone) and emit a jet, which later is deposited on a grounded collector. Ideally, before reaching the collector, the solvent is fully evaporated (Gunn \& Zhang, 2010). Further development of the electrospinning approach has allowed the formation of fibers with a core-shell structure by the coaxial method, a technique that uses two concentric needles with different diameters to simultaneously dispense two various fluids. This technique allows multiple drugs and/or diagnostic agents to be loaded into a single nanofiber with precise control of spatial location (Son et al. 2014; Zhang et al., 2016). For instance, the shell can act as a barrier to slow the release of a core-loaded drug. Localized drug delivery can also be achieved, which can allow a decrease in the required dose and provide more effective therapy with reduced side effects.

Here, we use two model drugs. The first, 5-fluorouracil $(5 \mathrm{FU})$, is an antimetabolism pyrimidine that inhibits cancer cell growth. It is a very low molecular weight drug, and its aqueous solubility is relatively high at low $\mathrm{pH}$. Although it has been widely used in the treatment of breast, colorectal, gastrointestinal and ovarian cancer, 5FU has a short-biological half-life and usually is given in high doses, which induces systemic toxicity (Illangakoon et al., 2015; Wang et al., 2016). The second, ferulic acid (FA), is a hydrophobic phenolic compound found in many plant tissues and which has a potential anticancer effect due to its antioxidant activity, allowing it to scavenge free radicals and regulate cell growth and proliferation (Ghosh et al., 2017). An antiproliferative effect of FA has been reported in various cancer cell lines (Mancuso \& Santangelo, 2014; Roy et al., 2016; Vashisth et al., 2015). 
Systemic administration of anticancer agents can be problematic owing to the fact that they typically have poor solubility and/or stability in the biological environment; often there is a low local concentration at the tumor site, which leads to reduced efficacy and severe side effects on healthy tissues (Zamani et al., 2013). These effects can be reduced by preparing systems which deliver the drug specifically to the site of action. One route to achieve this is through the generation of electrospun fibers. For instance, indomethacin and sodium diclofenac were successfully fabricated into nanofibers for colonic drug delivery (Akhgari et al., 2017; Shen et al., 2011). Studies to target 5-fluorouracil and ferulic acid (FA) delivery to the colon by electrospinning have also been reported (Illangakoon et al., 2015; Shen et al., 2011). Research conducted by Wang et al. (2015) prepared FA-loaded shellac fibers by modified coaxial electrospinning and probed these for colon-targeted drug delivery. In vitro dissolution tests demonstrated that only a small amount of FA was released at $\mathrm{pH} 2$, while the sustained release was obtained at neutral $\mathrm{pH}$. The fact that electrospun materials generally comprise amorphous solid dispersions should also permit solubility to be increased.

An alternative approach to enhance solubility is to use cyclodextrins (CDs), a family of cyclic oligosaccharides with hydrophilic exteriors, and relatively hydrophobic cavities. CDs can interact with hydrophobic molecules to form inclusion complexes via the formation of noncovalent bonds. The complexation of a drug with a CD also offers benefits in terms of stability, bioavailability, and absorption enhancement (Wang et al., 2016). The most common $\mathrm{CD}$ used in drug formulation is hydroxypropyl- $\beta$-cyclodextrin $(\mathrm{HP} \beta \mathrm{CD}$ ), a derivative of $\beta C D$ containing seven glucopyranose units. Wang et al. (2016) have previously proved that $5 \mathrm{FU}$ encapsulated in $\beta-C D$ derivatives showed improvements in dissolution properties over the pure drug. Another study investigated FA incorporated into $\beta$ - and $\gamma-\mathrm{CD}$ inclusion complexes and showed that the water solubility of FA was significantly improved by dint of complex formation (Casolaro et al., 2005; Wang et al., 2011).

The approach of preparing electrospun nanofibers with drug-cyclodextrin inclusion complexes has been reported previously, and found to be potent in enhancing the drug release from fibers loaded with sulfisoxazole (Aytac et al., 2015) and ciprofloxacin (Aytac et al., 2019). Coreshell nanofibers with the core composed of a curcumin$\mathrm{CD}$ inclusion complex and the shell a blank polymer have also been successfully fabricated (Aytac \& Uyar, 2017). A recent review discusses the electrospinning of CDs in detail (Topuz \& Uyar, 2019).

In this work, 5FU and FA were first encapsulated into $\mathrm{CD}$ complexes to enhance their solubility and dissolution rate (Casolaro et al., 2005; Wang et al., 2016). The drug$\mathrm{CD}$ composites were then processed, together with a gadolinium-based magnetic resonance imaging (MRI) agent, into the core of coaxial electrospun fibers. The shell comprised a $\mathrm{pH}$-sensitive polymer. These systems were fabricated with the ultimate aim of developing a theranostic system.

\section{MATERIALS AND METHODS}

\section{Materials}

The following were procured for this work: 5-fluorouracil (5FU, 99\%, Acros Organics), ferulic acid (FA, 98\%, Chem Cruz), hydroxypropyl-beta-cyclodextrin (HP $\beta C D$, Sigma Aldrich), hydroxypropyl-gamma-cyclodextrin (HP $\gamma \mathrm{CD}$, Sigma Aldrich), polyethylene oxide (PEO, Mw 600,000, Acros Organics and Mw 100,000, Sigma Aldrich), diethylenetriaminepentaacetic acid gadolinium (III) hydrate (GdDTPA, 97\%, Sigma Aldrich), Eudragit S100 (MW 125,000, Röhm GmbH), ethanol (99.8\%, Fisher Scientific Ltd), N,N-dimethyl acetamide (DMAc, 99.8\%, Sigma Aldrich), hydrochloric acid ( $\mathrm{HCl}, 37 \%$, Sigma Aldrich), and phosphate-buffered saline tablets (PBS, VWR). These were used as received without any further purification. All other chemicals used were analytical grade.

\section{Preparation of Electrospinning Solutions}

In all cases, the fiber shell solution comprised $15 \% \mathrm{w} / \mathrm{v}$ Eudragit S100 (ES-100) in ethanol: DMAc (9:1 v/v). To prepare the core solution, drug-cyclodextrin complexes were first generated by dissolving $\mathrm{HP} \beta \mathrm{CD}$ or $\mathrm{HP} \gamma \mathrm{CD}$ in water, then adding the drug at a 1:1 molar ratio. The solution was stirred for $12 \mathrm{~h}$ to ensure complex formation between the drug and cyclodextrin. A solution of PEO in ethanol was prepared, and then added to the inclusion complex solution or a solution of the pure drug to give a final polymer concentration of $1 \%$ or $3 \% \mathrm{w} / \mathrm{v}$, and stirring continued for $2 \mathrm{~h}$ The drug concentration in the final solution was $10 \% \mathrm{w} / \mathrm{w}$ with respect to $\mathrm{PEO}$, and the solvent comprised 3:7 v/v water:ethanol. Finally, 10\% GdDTPA (w/w, with respect to PEO) was added to the solution.

\section{Formation of Drug-Cyclodextrin Inclusion Complexes}

To confirm their formation, the inclusion complexes were isolated in powder form. HP $\beta C D$ or HP $\gamma C D$ was dissolved in water, and then the drug (5FU or FA) added to the solution at a molar ratio of $1: 1$. The solution was stirred for $12 \mathrm{~h}$ to ensure complex formation between the drug and the cyclodextrin. The solid inclusion complex was recovered by rotary evaporation at $45{ }^{\circ} \mathrm{C}$ (Butchi R-300 instrument). 
Table 1. Details of the formulations prepared

\begin{tabular}{llll}
\hline \multirow{2}{*}{ Formulation } & \multicolumn{3}{c}{ Core } \\
\cline { 2 - 4 } & Drug & CD & Polymer solution \\
\hline F1a & FFU & HPßCD & $3 \% \mathrm{w} / \mathrm{v}$ PEO $0.6 \mathrm{M}$ \\
F1b & $5 F U$ & - & $3 \% \mathrm{w} / \mathrm{v}$ PEO $0.6 \mathrm{M}$ \\
F2a & FA & HP $\gamma C D$ & $3 \% \mathrm{w} / \mathrm{v}$ PEO $0.6 \mathrm{M}$ \\
F2b & FA & - & $3 \% \mathrm{w} / \mathrm{v}$ PEO $0.6 \mathrm{M}$ \\
F3a & FA & HP $\gamma C D$ & $1 \% \mathrm{w} / \mathrm{v}$ PEO $0.6 \mathrm{M}$ \\
F3b & FA & - & $1 \% \mathrm{w} / \mathrm{v}$ PEO $0.6 \mathrm{M}$ \\
F4a & FA & HP $\gamma C D$ & $1 \% \mathrm{w} / \mathrm{v}$ PEO $0.1 \mathrm{M}$ \\
F4b & FA & - & $1 \% \mathrm{w} / \mathrm{v}$ PEO $0.1 \mathrm{M}$ \\
\hline
\end{tabular}

\section{Electrospinning}

Coaxial electrospinning was performed to produce the fibers. The setup consisted of a high voltage power supply (FuG Elektronik HCP35-35000) and two syringe pumps (KDS100, Cole-Parmer), which were connected to $5 \mathrm{~mL}$ syringes. The latter was used to eject the core and shell solutions at constant rates through a coaxial spinneret (20- and 17-gauge needles were used to dispense the core and shell fluids, respectively). The fibers formed were collected on a grounded flat plate, which was wrapped in aluminum foil and placed at a distance of $25 \mathrm{~cm}$ from the tip of the needle. The voltage was set to $15 \mathrm{kV}$, the core solution flow rate at $0.3 \mathrm{~mL} / \mathrm{h}$, and the shell solution flow rate at $1.5 \mathrm{~mL} / \mathrm{h}$. All experiments were conducted at $25 \pm$ $3{ }^{\circ} \mathrm{C}$ and $32-45 \%$ relative humidity. After production, the fibers were wrapped in aluminum foil and placed in a vacuum desiccator for at least $24 \mathrm{~h}$ to ensure complete evaporation of the solvents. A series of formulations were developed, as detailed in Table 1 .

\section{Characterization}

The morphology of the fibers was investigated by scanning electron microscopy (SEM, FEI Quanta 200 FEG ESEM) and transmission electron microscopy (TEM, Philips/FEI CM120 Bio Twin microscope). The diameter of the fibers was calculated from the SEM images by using the ImageJ Software (National Institutes of Health) to measure the fibers at more than 100 points in the images, and the results were given as mean \pm S.D. For TEM analysis, samples were collected directly on TEM grids during the electrospinning process. A fluorescence microscope $\left(\mathrm{EVOS}^{\circledR} \mathrm{FL}\right.$ Cell Imaging System, ThermoFisher Scientific) with a GFP filter and a digital camera attached was also used to analyze the samples.

X-ray diffraction (XRD) patterns were recorded using a Miniflex 600 diffractometer (Rigaku) supplied with $\mathrm{Cu}$ $\mathrm{K} \alpha$ radiation. Patterns were obtained over the $2 \theta$ range $5-30^{\circ}$ at a speed of $5^{\circ}$ per minute (size step $0.02^{\circ}$ ).
The generator voltage was $40 \mathrm{kV}$ and current $15 \mathrm{~mA}$. IR spectra were obtained on a Perkin-Elmer Spectrum 100 instrument, with scans recorded over the range 550 $-4000 \mathrm{~cm}^{-1}$ and the resolution set at $4 \mathrm{~cm}^{-1}$. Differential scanning calorimetry (DSC) was performed with a TA Instruments Q2000 calorimeter. Experiments were carried out with a temperature ramp of $10^{\circ} \mathrm{C} / \mathrm{min}$ under a $50 \mathrm{~mL} / \mathrm{min}$ flow of nitrogen, from 25 to $200^{\circ} \mathrm{C}$ or $300^{\circ} \mathrm{C}$. The CD-drug inclusion complexes were characterized by SEM, XRD, and IR spectroscopy using the same methods as detailed above.

\section{In Vitro Drug Release}

An in vitro drug release study was performed by first putting approximately $50 \mathrm{mg}$ of fibers in $50 \mathrm{~mL}$ of $0.1 \mathrm{~N}$ aqueous $\mathrm{HCl}$ for $2 \mathrm{~h}$, and then transferring them to $50 \mathrm{~mL}$ of phosphate-buffered saline (PBS; $\mathrm{pH}$ 7.0) for a further $22 \mathrm{~h}$. The experiments were performed at $37^{\circ} \mathrm{C}$, and the stirring speed was set at $50 \mathrm{rpm}$. At pre-determined time intervals, $3 \mathrm{~mL}$ aliquots were withdrawn and replaced with fresh medium. The drug concentration in the medium was quantified using a UV spectrophotometer (Agilent Technologies Cary UV 100) at $322 \mathrm{~nm}$ (FA) or $266 \mathrm{~nm}(5 \mathrm{FU})$. All experiments were performed in triplicate.

\section{RESULTS AND DISCUSSION}

\section{Formation of Drug-Cyclodextrin Inclusion Complexes}

\section{FTIR spectroscopy}

The FTIR spectra of 5FU- HP $\beta C D$ (Figure 1a) and FA-HP $\gamma C D$ (Figure $1 b$ ) revealed that both HP $\beta C D$ and $\mathrm{HP} \gamma \mathrm{CD}$ displayed similar features: a broad peak at 3028 $-3650 \mathrm{~cm}^{-1}$ corresponds to $\mathrm{O}-\mathrm{H}$ stretching, the band at $2928-2920 \mathrm{~cm}^{-1}$ to $\mathrm{C}-\mathrm{H}$ stretching vibrations, and peaks between $1425-1456 \mathrm{~cm}^{-1}$ to $\mathrm{C}-\mathrm{H}$ and $\mathrm{C}-\mathrm{O}$ vibrations. An additional absorbance at $1020 \mathrm{~cm}^{-1}$ arised due to the C-O-C linkage (Wang et al., 2011). In the 5FU spectrum 


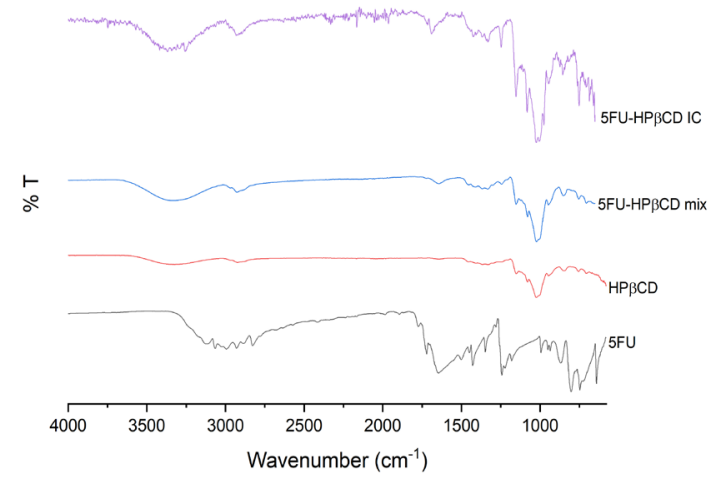

(a)

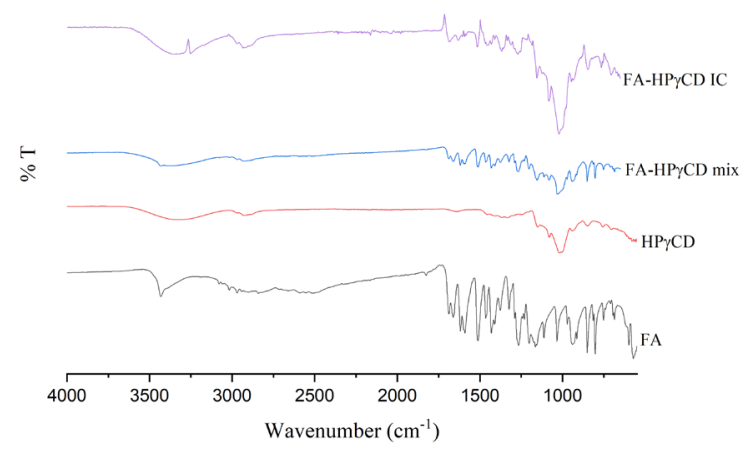

(b)

Figure 1. FTIR Spectra of 5FU, HP 3 CD, 5FU-HPßCD mixture and 5FU-HPßCD inclusion complex (a); and FTIR spectra of FA, HP $\gamma C D$, FA-HP $\gamma$ CD mixture and FA-HP $\gamma$ CD inclusion complex (b)

(Figure 1a), peaks at $2828-3125 \mathrm{~cm}^{-1}$ represent $\mathrm{C}-\mathrm{H}$ and $\mathrm{N}-\mathrm{H}$ stretching, bands at 1711 and $1655 \mathrm{~cm}^{-1}$ were assigned to $\mathrm{C}=\mathrm{O}$ stretching, while a $\mathrm{C}-\mathrm{N}$ stretch could be seen at $1244 \mathrm{~cm}^{-1}$ and a C-F stretch at $998 \mathrm{~cm}^{-1}$ (Illangakoon et al., 2015). The peaks in the range 1429 $-1244 \mathrm{~cm}^{-1}$ corresponded to the substituted pyrimidine group (Di Donato et al., 2016). The formation of drugcyclodextrin complexes is typically manifested through the shifting and/or weakening of distinctive bands from the active ingredient and cyclodextrin (Aytac et al. 2018, Zidane et al., 2016). The spectrum of a physical mixture of 5FU and HPßCD (Figure 1a) showed as expected, a simple juxtaposition of the features of the two raw materials. The IR spectrum of the 5FU-HP $\beta C D$ inclusion complex mainly revealed the peaks of pure HP $\beta C D$, with some shifting of the 5FU peaks also observed. Many of the characteristic peaks of $5 \mathrm{FU}(\mathrm{N}-\mathrm{H}, \mathrm{C}-\mathrm{N}, \mathrm{C}-\mathrm{F}$, and substituted pyrimidine peaks at $3125-2828 \mathrm{~cm}^{-1}, 998$ $\mathrm{cm}^{-1}$ and $1429-1244 \mathrm{~cm}^{-1}$, respectively) cannot be seen due to the overlapping with the CD bands (Di Donato et al., 2016; Illangakoon et al., 2015). However, the peaks at 1711 and $1655 \mathrm{~cm}^{-1}$ from 5FU were still present in the IR pattern of the complex but shifted to 1722 and $1688 \mathrm{~cm}^{-}$ ${ }^{1}$, respectively (cf. the spectrum of a physical mixture), indicating interactions between the $\mathrm{C}=\mathrm{O}$ group of $5 \mathrm{FU}$ and $\mathrm{HP} \beta \mathrm{CD}$. The $5 \mathrm{FU}-\mathrm{HP} \beta \mathrm{CD}$ spectrum obtained is an agreement with results from previous work (Wang et al., 2016).

In the FTIR spectrum of FA (Figure 1b), the aromatic group gave peaks at $1619,1592,1510$, and $1431 \mathrm{~cm}^{-1}$. The hydroxyl groups from the alcohol and carboxylic acid groups stretched in the range $2500-3437 \mathrm{~cm}^{-1}$ with a prominent peak at $3431 \mathrm{~cm}^{-1}$, and vibrations at $1267 \mathrm{~cm}^{-1}$ were due to the ether linkage (C-O-C stretch). There were $\mathrm{C}=\mathrm{O}$ stretches at $1689 \mathrm{~cm}^{-1}$ and $\mathrm{C}=\mathrm{C}$ stretches at $1659 \mathrm{~cm}^{-1}$ (Vashisth et al., 2015; Wang et al., 2011; Yang et al., 2013). Unlike the spectrum of a FA-HP $\gamma$ CD physical mixture, which showed strong signals from the FA phenyl ring, the IR spectrum of FA$\mathrm{HP} \gamma \mathrm{CD}$ complex mostly resembles that of HP $\gamma \mathrm{CD}$. The bands distinctive for the aromatic ring of FA (at 1619 $-1431 \mathrm{~cm}^{-1}$ ) as well as the two bands at $851 \mathrm{~cm}^{-1}$ and 802 $\mathrm{cm}^{-1}$ from phenyl $\mathrm{C}-\mathrm{H}$ groups on FA were shifted and diminished. This arises due to the complexation of FA into the $\mathrm{HP} \gamma \mathrm{CD}$ cavity and overlap with the peaks from $\mathrm{HP} \gamma \mathrm{CD}$. However, a characteristic signal at $1689 \mathrm{~cm}^{-1}$ belonging to the carbonyl group of FA is still observed. These observations show that the FA-HP $\gamma \mathrm{CD}$ inclusion complex was successfully formed. This result is also in agreement with studies conducted by Wang et al. (2011) and Casolaro et al. (2005).

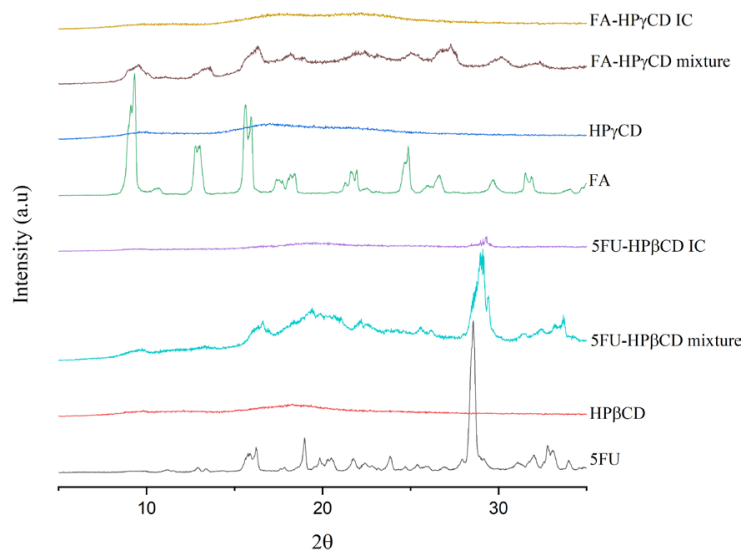

Figure 2. XRD patterns of the drugs, cyclodextrins, drug-cyclodexterin mixtures and drug-cyclodextrin inclusion complexes

\section{XRD patterns}

XRD patterns were presented in Figure 2. HP $\beta C D$ and $\mathrm{HP} \gamma \mathrm{CD}$ showed broad haloes in their pattern, as is typical for amorphous materials. Bragg reflections from $5 \mathrm{FU}$ were observed at $2 \theta=16^{\circ}, 18^{\circ}, 20^{\circ}, 22^{\circ}, 24^{\circ}, 28^{\circ}$, $32^{\circ}$, and $34^{\circ}$ (Wang et al., 2016). FA shows reflections at $2 \theta=8^{\circ}, 13^{\circ}, 16^{\circ}, 18^{\circ}, 22^{\circ}, 26^{\circ}, 29^{\circ}$ and $32^{\circ}$ (Wang et al., 2011). These sharp Bragg reflections arise due to 


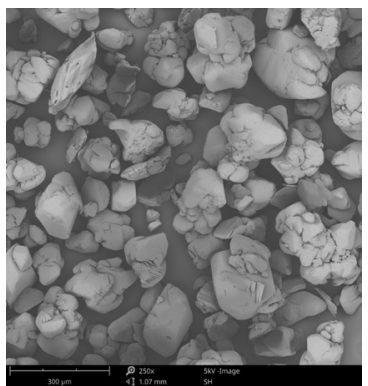

(a)

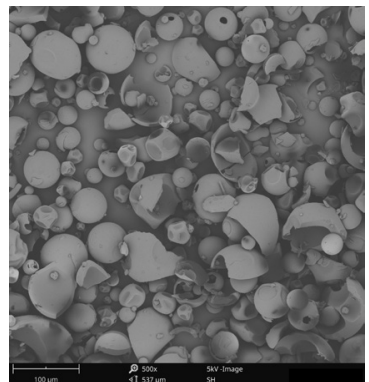

(b)

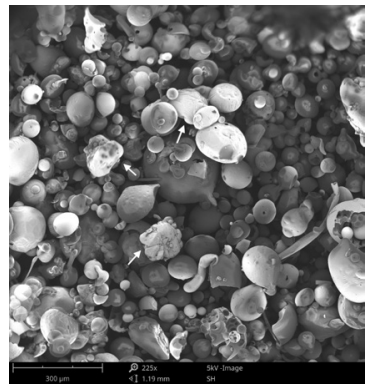

(c)

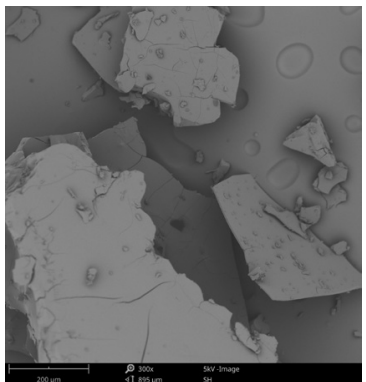

(d)

Figure 3. SEM micrographs of 5FU (a), HPßCD (b), physical mixtures of 5FU-HPßCD (c), 5FU-HPßCD inclusion complexes (d).

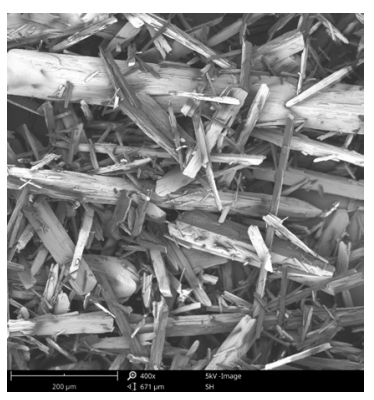

(a)

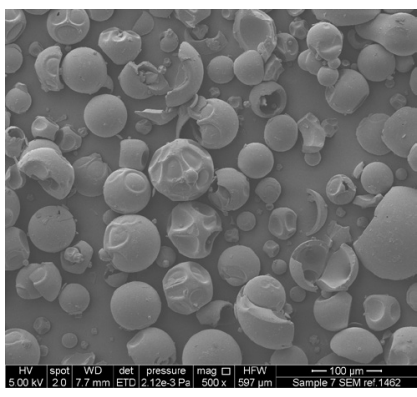

(b)

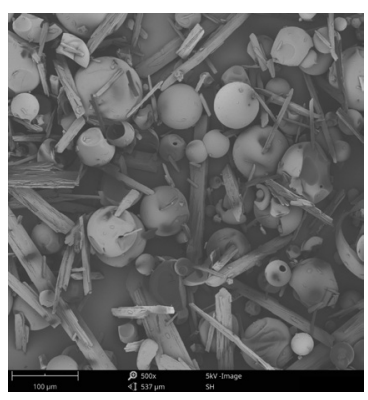

(c)

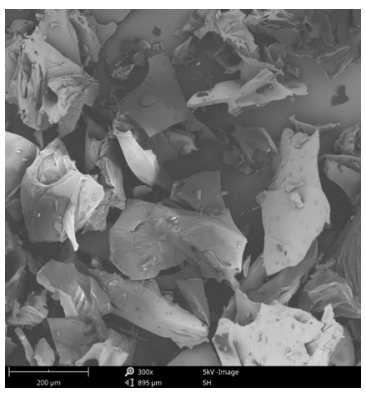

(d)

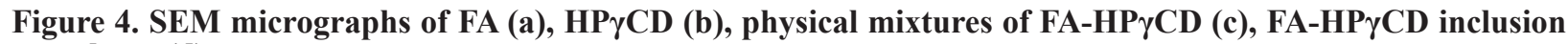
complexes (d)

the pure drug species comprising crystalline materials. Physical mixtures of the drug and cyclodextrin still contained distinctive reflections from pure drugs. In contrast, the 5FU-HP $\beta C D$ and FA-HP $\gamma$ CD inclusion complexes have XRD patterns comprising broad haloes; the characteristic reflections of both 5FU and FA are absent, which confirms successful complexation (Anselmi et al., 2006).

\section{Morphology}

The surface morphology of the raw materials, physical mixtures, and inclusion complexes were assessed by SEM. Figure 3 showed that 5FU exists as large (ca. 100 $-200 \mu \mathrm{m})$ particles with irregular shapes, while HP $\beta C D$ comprised amorphous-looking approximately spherical particles. A physical mixture of 5FU and HP $3 C D$ did not show any significant changes in morphology, and 5FU particles could be seen to be mixed with the $\mathrm{HP} \beta \mathrm{CD}$ particles. In contrast, the $5 \mathrm{FU}-\mathrm{HP} \beta \mathrm{CD}$ inclusion complexes took the form of large $(>200 \mu \mathrm{m})$ particles with a very different morphology to the precursors. These SEM results were in agreement with previous research by Wang et al. (2016). The same trends were seen for FA (Figure 4). Pure FA comprised needle-like crystals, while $\mathrm{HP} \gamma \mathrm{CD}$ took the form of amorphouslooking spherical particles. In the physical mixture of FA and HP $\gamma \mathrm{CD}$, FA crystals were clearly observed to be mixed with $\mathrm{HP} \gamma \mathrm{CD}$, without any changes in morphology. The inclusion complexes consisted of irregular shaped

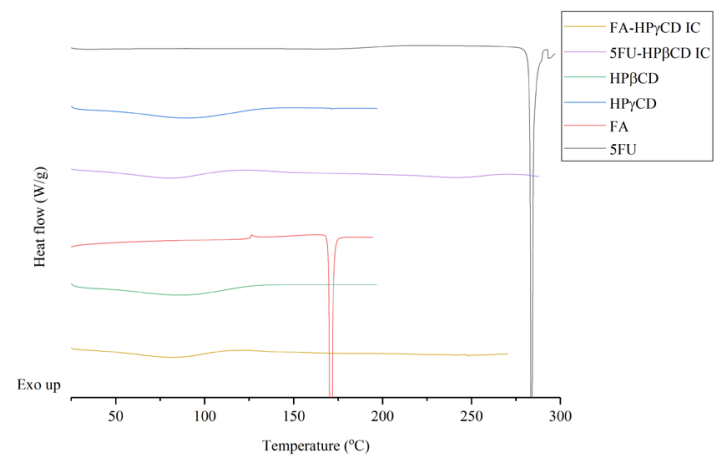

Figure 5. DSC data of the drugs, cyclodextrins and drug-cyclodextrin inclusion complexes

particles having very different morphology to FA and $\mathrm{HP} \gamma \mathrm{CD}$, with sizes around $100-300 \mu \mathrm{m}$. These observations again confirmed the formation of the drugcyclodextrin inclusion complex.

\section{DSC data}

DSC data of the drugs and complexes were given in Figure 5. 5FU shows a melt at $283.5^{\circ} \mathrm{C}$, in accordance with the results of Illangakoon et al. (2015). This verified that the drug exists in the crystalline form, as indicated by XRD. FA shows a sharp endothermic peak at 173.2 ${ }^{\circ} \mathrm{C}$, similar to results obtained by Anselmi et al., (2006). This peak corresponded to the FA melting point, again consistent with the XRD data. Both HP $\beta C D$ and HP $\gamma C D$ 
Table 2. The diameters of the formulated fibers

\begin{tabular}{lllll}
\hline \multirow{2}{*}{ Formulation } & \multicolumn{4}{c}{ Core } \\
\cline { 2 - 4 } & Drug & CD & Polymer & Diameter $(\boldsymbol{\mu m})$ \\
\hline F1a & $5 \mathrm{FU}$ & - & $3 \% \mathrm{w} / \mathrm{v}$ PEO 0.6M & $3.65 \pm 1.20$ \\
F1b & $5 \mathrm{FU}$ & $\mathrm{HP} \beta \mathrm{CD}$ & $3 \% \mathrm{w} / \mathrm{v}$ PEO 0.6M & $4.24 \pm 1.23$ \\
F2a & FA & - & $3 \% \mathrm{w} / \mathrm{v}$ PEO 0.6M & $3.74 \pm 1.13$ \\
F2b & FA & HP $\gamma \mathrm{CD}$ & $3 \% \mathrm{w} / \mathrm{v}$ PEO 0.6M & $5.08 \pm 1.28$ \\
& & & & \\
F3a & FA & - & $1 \% \mathrm{w} / \mathrm{v}$ PEO 0.6M & $1.41 \pm 0.59$ \\
F3b & FA & HP $\gamma \mathrm{CD}$ & $1 \% \mathrm{w} / \mathrm{v}$ PEO 0.6M & $2.42 \pm 0.57$ \\
F4a & FA & - & $1 \% \mathrm{w} / \mathrm{v}$ PEO 0.1M & $2.96 \pm 0.78$ \\
F4b & FA & HP $\gamma \mathrm{CD}$ & $1 \% \mathrm{w} / \mathrm{v}$ PEO 0.1M & $4.57 \pm 1.00$ \\
\hline
\end{tabular}

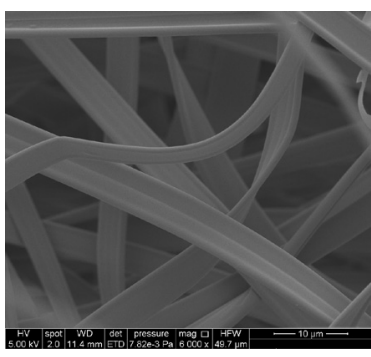

(a)

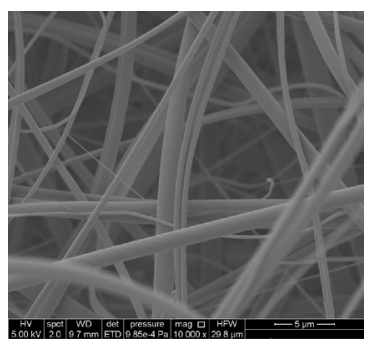

(e)

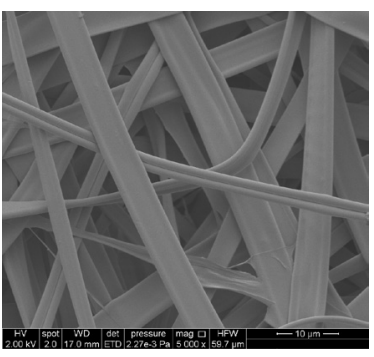

(b)

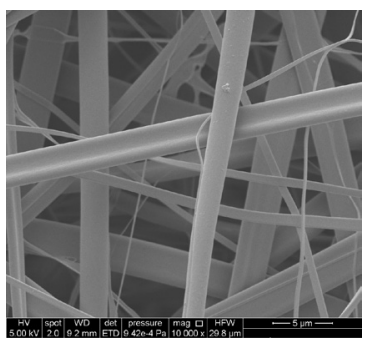

(f)

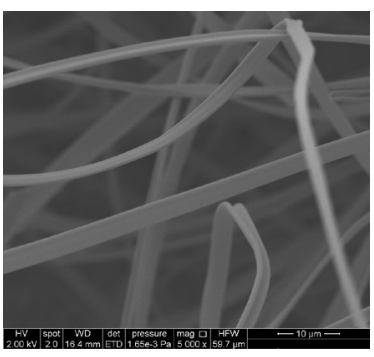

(c)

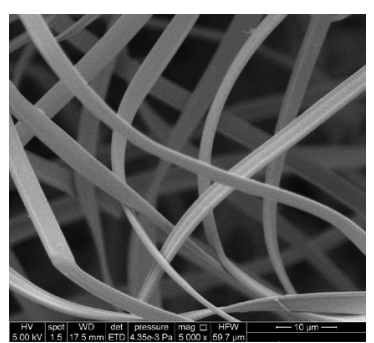

(g)

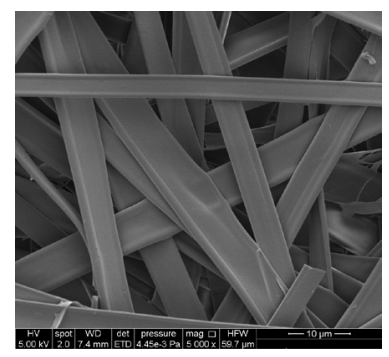

(d)

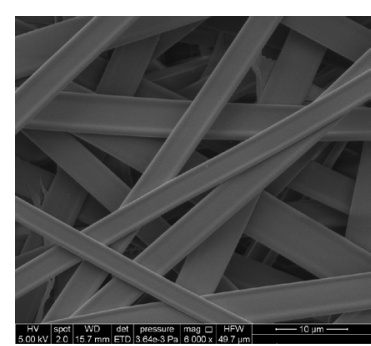

(h)

Figure 6. SEM images of the fibers F1a (a), F1b (b), F2a (c), F2b (d), F3a (e), F3b (f), F4a (g), and F4b (h) prepared in this work

showed broad endotherms in the temperature range $75-125^{\circ} \mathrm{C}$ corresponding to the loss of sorbed water, which was in agreement with previous work (Wang et al., 2016). The DSC traces of the inclusion complexes did not show any melting endotherms from 5FU or FA, indicating that the drugs were successfully incorporated in the cyclodextrin derivatives to generate amorphous formulations, as was also evidenced by XRD.

\section{Electrospun Fibers}

\section{Fiber morphology}

SEM images of the fibers were displayed in Figure 6. The fibers were smooth and bead-free with no drug crystals visible, indicating that $5 \mathrm{FU}$ and $\mathrm{FA}$ had been successfully encapsulated in the fibers. All the fibers were flat and ribbon-like, with diameters in the range of 1.41 to $5.08 \mu \mathrm{m}$ (Table 2). The flat shape was expected to arise because when the polymer solution was ejected, the shell solvent on the outer part of the jet solution was rapidly evaporated, and a thin polymer skin with a liquid core was formed. This was to be expected given that the core contains water, which is much less volatile than the ethanol used to prepare the shell solution. After the polymer jet reached the collector, the solvent inside subsequently evaporated, and the cylindrical shape of the fiber thus collapsed, resulting in a ribbon-like shape (Baji et al., 2010; Huang et al., 2006).

Overall, the diameters of fibers containing the cyclodextrin inclusion complex were larger than the free-drug formulations (Table 2). This result was 


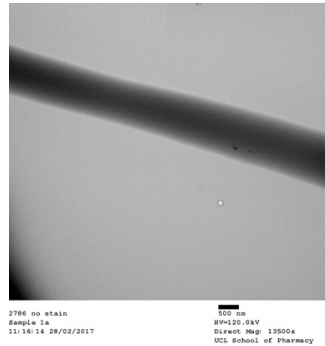

(a)

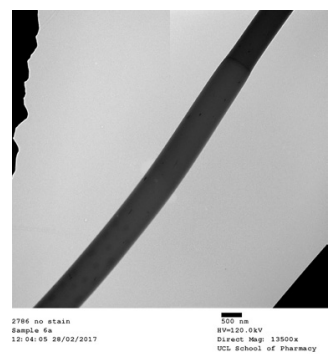

(e)

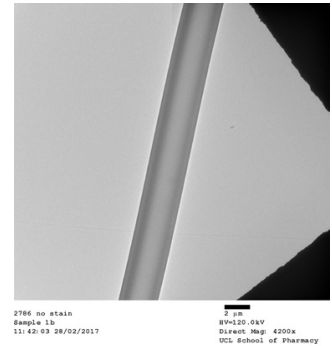

(b)

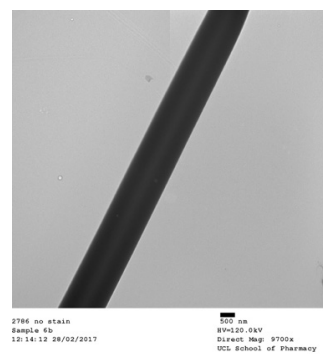

(f)

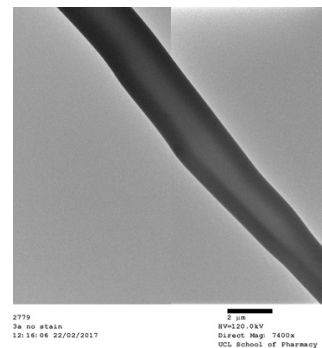

(c)

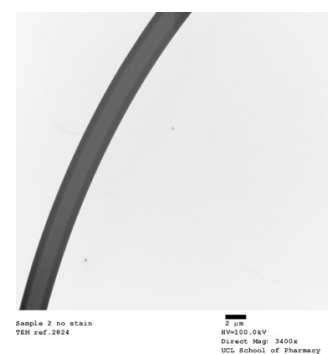

(g)

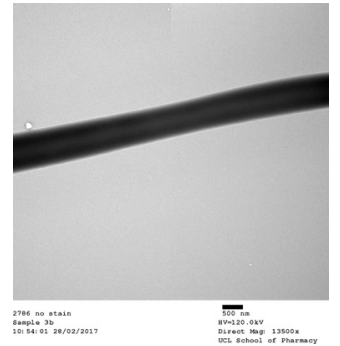

(d)

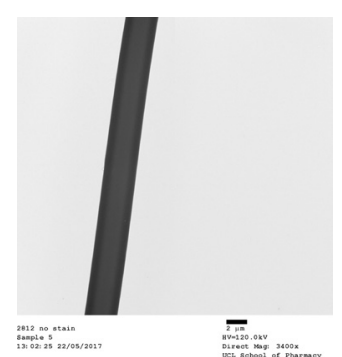

(h)

Figure 7. TEM images of fibers F1a (a), F1b (b), F2a (c), F2b (d), F3a (e), F3b (f), F4a (g), and F4b (h) prepared.

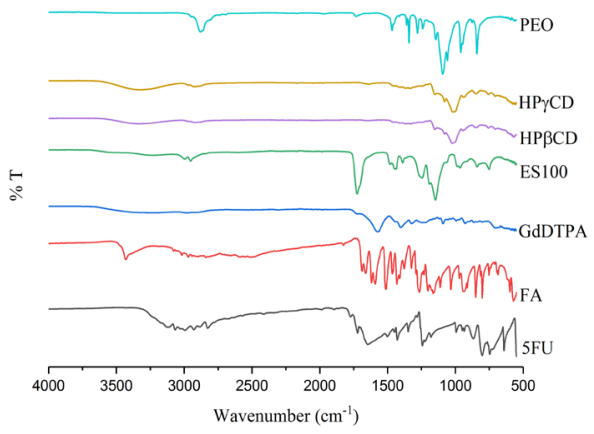

(a)

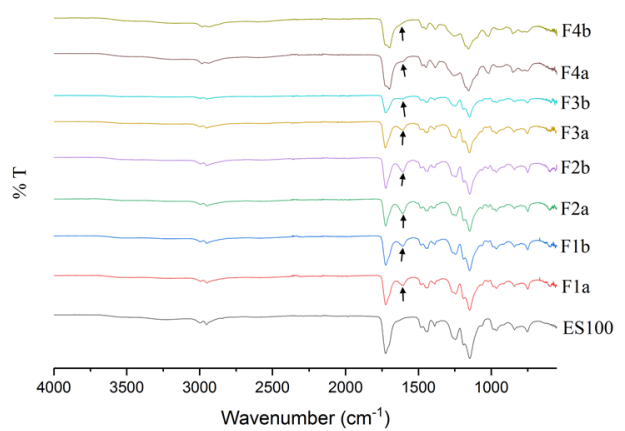

(b)

Figure 8. FTIR spectra of the raw materials (a), and the fibers (b).

consistent with a previous study by Samprasit et al., (2015). These authors ascribed the larger diameter of the drug-cyclodextrin inclusion complex systems to be a result of the higher viscosity of the solution with the CD present, which led to a greater amount of polymer chain entanglement in the solution and thus bigger fibers (Huang et al., 2006; Samprasit et al., 2015). Larger diameter fibers were also observed with a higher molecular weight of PEO in the core.

In order to observe the internal structure of the fibers, TEM analysis was conducted. As shown in Figure 7, all of the formulations had clear core-shell structures.

\section{FTIR spectra}

IR spectra of the raw materials were given in Figure 8a. The characteristic peaks at $1571 \mathrm{~cm}^{-1}$ and $1405 \mathrm{~cm}^{-1}$ in the Gd(DTPA) spectrum were due to asymmetric and symmetric COO stretching vibrations (Huang et al., 2006). In the spectrum of PEO, the peak at $2882 \mathrm{~cm}^{-1}$ was due to $\mathrm{C}-\mathrm{H}$ stretching, and that at $1095 \mathrm{~cm}^{-1}$ was assigned to C-O-C stretching (Krstic et al., 2017). ES-100 exhibited characteristic vibrations from $\mathrm{C}-\mathrm{H}$ stretching at $2997 \mathrm{~cm}^{-1}$ and $2952 \mathrm{~cm}^{-1}, \mathrm{C}=\mathrm{O}$ stretching at $1724 \mathrm{~cm}^{-}$ 1, and C-O-C stretching (ester linkage) at $1257 \mathrm{~cm}^{-1}$ and $1148 \mathrm{~cm}^{-1}$ (Illangakoon et al., 2015). Figure 8b showed the spectra of the fibers. The major peaks were visible at 1724,1257 , and $1148 \mathrm{~cm}^{-1}$ corresponded to ES-100. A band at ca. $1000 \mathrm{~cm}^{-1}$ attributed to the C-O-C linkage of PEO was also observed. Further, an intensified peak at $1608-1612 \mathrm{~cm}^{-1}$ could be seen in the fibers' spectra, which was due to the $\mathrm{C}=\mathrm{O}$ groups of $5 \mathrm{FU}$ (F1a, F1b) or FA (F2a-F4d). This showed that the drugs and drugcyclodextrin complexes were successfully incorporated into the fiber system. These findings were in agreement with the literature (Jin et al., 2016). 


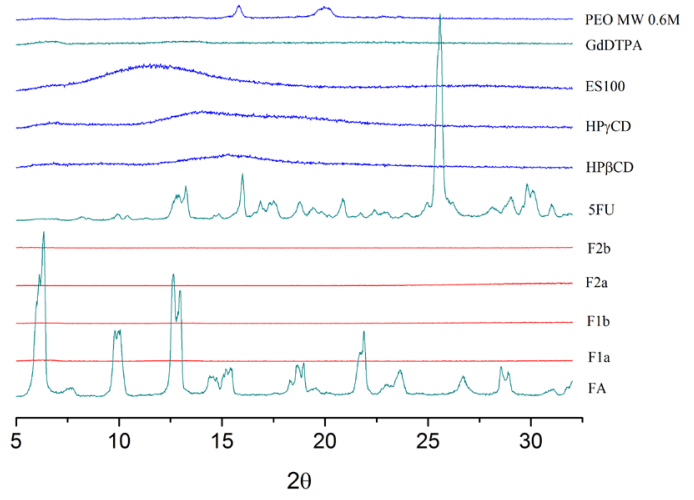

Figure 9. XRD patterns of the fibers and raw materials

\section{$X R D$}

XRD patterns (Figure 9) demonstrated that ES-100 was an amorphous material, with no distinct Bragg reflections in its pattern. PEO exhibited two peaks at $19^{\circ}$ and $23^{\circ}$, as a result of its semi-crystalline structure (Azli et al., 2015; Pandey et al., 2009). All the fibers had characteristic XRD patterns of amorphous systems, with only broad haloes visible. The drug molecules or complexes were thus distributed in the fibers in an amorphous state. This agreed with the results of previous studies: it is well known that the electrospinning process typically prevents crystallization because of the very rapid solvent evaporation process (Aytac et al., 2015; Aytac et al., 2016).

\section{DSC}

From the DSC data (Figure 10a-b), it could be seen that Eudragit S100 had a broad endothermic peak over the temperature range 55 to $125^{\circ} \mathrm{C}$, consistent with the literature (Illangakoon et al., 2015) and showing the loss of absorbed and adsorbed water (Mithu et al., 2017). PEO exhibited a sharp endothermic peak at $68^{\circ} \mathrm{C}$, corresponding to its melting transition from

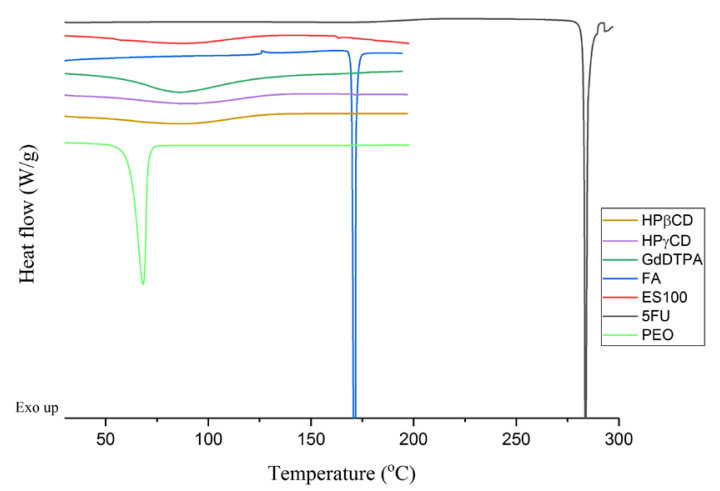

(a) semi-crystalline form (Jin et al., 2016; Krstic et al., 2017). However, the endothermic peak of PEO could not be seen in the fiber traces, indicating the format of the core-shell system. This was consistent with the previous study for PEO/ES100 core-shell system by Jin et al. (2016). All of the fiber formulations showed a broad endothermic peak over the temperature range from around 50 to $140^{\circ} \mathrm{C}$, which was attributed to the loss of water. No melting endotherms from the drug contents were seen, confirming the fibers to exist as amorphous solid dispersions.

\section{Drug Release Study}

Drug release data were given in Figure 11. Eudragit S100, which comprised the shell, was only soluble above $\mathrm{pH} 7.0$ and therefore was expected to be able to prevent the release of the drug in the initial low $\mathrm{pH}$ environment (Mithu et al., 2017). Unexpectedly however, all the formulations released their drug cargo rapidly in low $\mathrm{pH}$ conditions. More than $80 \%$ of the drug loading was released in $30 \mathrm{~min}$, and within $1 \mathrm{~h}$ essentially $100 \%$ release was reached. The release study of F3a and F4a were not conducted as F1a and F2a showed similar burst release result. The release of 5FU can be explained by a similar rationale to that proposed by Illangakoon et al. (2015): $5 \mathrm{FU}$ is a low molecular weight drug and has a relatively high solubility at low $\mathrm{pH}$, which gives it a propensity to detach from the cyclodextrin cage, penetrate through the fibers and dissolve into solution. However, the release of FA at $\mathrm{pH} 1$ was more confusing. To investigate this, SEM images of the fibers after $2 \mathrm{~h}$ immersion in $\mathrm{HCl}$ were obtained. The SEM images of F1b and F2b given in Figure 12 clearly showed the morphology of the fibers had changed after $2 \mathrm{~h}$ immersion in $0.1 \mathrm{~N} \mathrm{HCl}$. The smooth ribbon-like fibers had swollen and formed pores. This might arised due to the permeation of water into the fibers and PEO in the core swelling, which in turn caused the shell to rupture and yield pores that allow the

Figure 10. DSC data of the raw materials (a) and the fibers (b). 


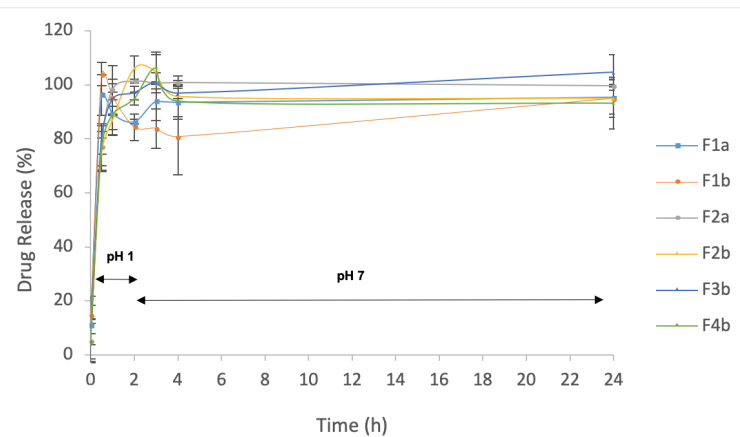

Figure 11. In vitro drug release from the fibers

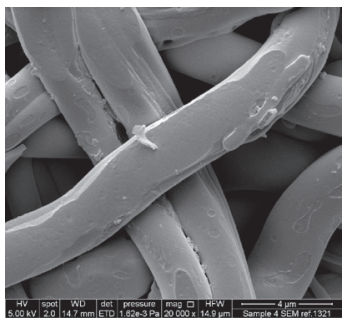

(a)

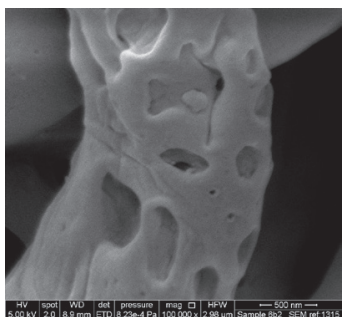

(b)
Figure 12. SEM images of F1b (a) and F2b (b) after 2 hours immersion in $\mathbf{H C l}$.

drugs to diffuse out of the polymer matrix. In addition, when we compared the drug-loaded (F1a) and drug-CD loaded (F1b) nanofibers, the solubility increment that was expected to be provided by cyclodextrin-inclusion complex formation was not observed.

The same release patterns of drug release were seen regardless of the drug loading and PEO molecular weight: F3b and F4b, which used a lower concentration of PEO than F2a and F2b (Table 1) did not give significantly different results to those of F1a,b, and F2a,b. SEM images of $\mathrm{F} 3 \mathrm{~b}$ and $\mathrm{F} 4 \mathrm{~b}$ after immersion in $\mathrm{HCl}$ showed smooth fibers without pores, however (Figure 13). Although the TEM results showed clear images of separate core and shell compartments, some mixing of the core and shell fluids might occur during electrospinning, since the solutions were prepared in miscible solvent systems. A similar hypothesis could also be drawn for F1a,b and F2a,b, but in these cases, it was clear that there were very marked changes in fiber morphology, which were likely to be at least partially responsible for the release pattern noted.

Therefore, we postulated that at least in the case of the F3a,b, and F4a, b fibers, some of the drug content might be present on the surface of the fibers. To probe this, we exploited the fact that FA was known to show bluegreen fluorescence (Inokuchi et al., 2016). Fluorescence microscopy images of the fibers (Figure 14) were recorded, and it was observed that intense fluorescence was visible at the exterior of the fibers. The intensity from

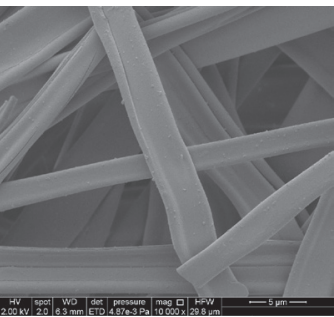

(a)

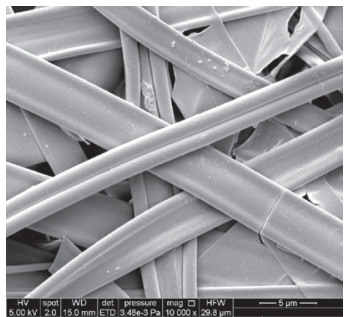

(b)
Figure 13. SEM images of F3b (a) and F4b (b) after 2 hours immersion in $\mathrm{HCl}$ (a).

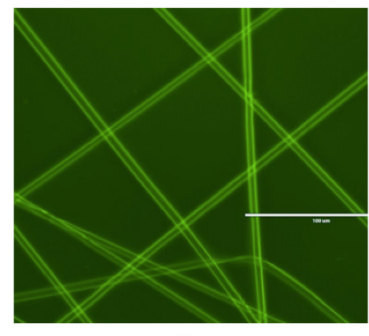

(a)

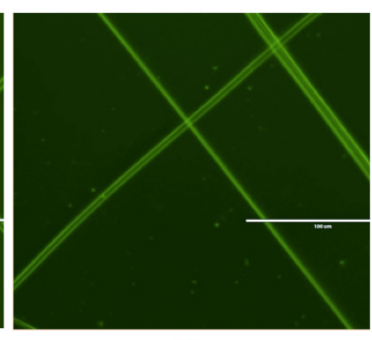

(b)
Figure 14. Fluorescence images of F3b (a) and F4b (b) fibers.

the fiber exterior was notably brighter than that from the interior, indicating that at least some of the drugs had migrated from the core to the shell.

This work, in conjunction with the previously reported findings of Illangakoon et al. (2015) indicated that great care must be taken when preparing core/shell fibers for $\mathrm{pH}$-triggered drug release. It is clear that a number of factors can cause the drug to be released from the fibers at low $\mathrm{pH}$, even if the drug is loaded only in the core solution, inclusion complexes are formed, and the shell is insoluble in acidic conditions. Cautious selection of the operating parameters and the solutions to be used in electrospinning is required to yield the required results.

\section{CONCLUSION}

A series of new formulations in the form of core-shell electrospun fibers was reported in this work. These contained anticancer drugs (5-fluorouracil or ferulic acid) or their cyclodextrin inclusion complexes, together with a gadolinium-based magnetic resonance imaging contrast agent, in the core. Their shell comprised Eudragit S100. SEM images showed the formation of smooth ribbon-like fibers, with diameters ranging from 1.41 to $5.08 \mu \mathrm{m}$, and a clear interface between core and shell compartments was observed by TEM. IR, XRD and DSC data confirmed the encapsulation of the drug into the cyclodextrin cavity and the formation of fibers comprising amorphous solid dispersions. Drug release from the systems at $\mathrm{pH} 1$ and 7 was also investigated. These showed that all the drug was released within one 
hour at $\mathrm{pH} 1$. This is attributed to the movement of drug from the core to the shell compartment of the fibers, and/ or the permeation of water into the core compartment causing this to swell and the fibers to burst.

\section{ACKNOWLEDGEMENTS}

We thank the Indonesia Endowment Fund for Education of the Republic of Indonesia (LPDP RI) for the award of a PhD studentship to Fatimah. We also thank the European Union Horizon 2020 programme for support for Zeynep Aytac to undertake research at UCL, funded by COST action MP1206.

\section{REFERENCES}

Aytac, Z., Sen, HS., Durgun, E. \& Uyat, T. (2015). Sulfisoxazole/cyclodextrin inclusion complex incorporated in electrospun hydroxypropyl cellulose nanofibers as drug delivery system. Colloids Surf B Biointerfaces, 128, 331-338.

Aytac, Z. \& Uyar, T. (2017). Core-shell nanofibers of curcumin/cyclodextrin inclusion complex and polylactic acid: Enhanced water solubility and slow release of curcumin. International Journal of Pharmaceutics, 518 (1-2), 177-184.

Aytac, Z., Calebioglu, A., Yildiz., ZI. \& Uyar, T. (2018). Efficient encapsulation of citral in fast-dissolving polymer-free electrospun nanofibers of cyclodextrin inclusion complexes: High thermal stability, longer shelf-life, and enhanced water solubility of citral. Nanomaterials (Basel), 8(10)

Aytac, Z., Ipek, S, Erol, I., Durgun, E., \& Uyar, T. (2019). Fast-dissolving electrospun gelatin nanofibers encapsulating ciprofloxacin/cyclodextrin inclusion complex. Colloids and Surfaces B: Biointerfaces, 1, 178, 129-136.

Akhgari, A., Heshmati, Z., Afrasiabi Garekani, H., Sadeghi, F., Sabbagh, A., Sharif Makhmalzadeh, B., \& Nokhodchi, A. (2017). Indomethacin electrospun nanofibers for colonic drug delivery: In vitro dissolution studies. Colloids and Surfaces B: Biointerfaces, 152, 29-35.

Anselmi, C., Centini, M., Ricci, M., Buonocore, A., Granata, P., Tsuno, T., \& Facino, R. M. (2006). Analytical characterization of a ferulic acid/??-cyclodextrin inclusion complex. Journal of Pharmaceutical and Biomedical Analysis, 40(4), 875-881.

Azli, A. A., Manan, N. S. A., \& Kadir, M. F. Z. (2015). Conductivity and dielectric studies of lithium trifluoromethanesulfonate doped polyethylene oxidegraphene oxide blend based electrolytes. Advances in Materials Science and Engineering, 2015(July).

Baji, A., Mai, Y. W., Wong, S. C., Abtahi, M., \& Chen, P. (2010). Electrospinning of polymer nanofibers: Effects on oriented morphology, structures, and tensile properties. Composites Science and Technology, 70(5), 703-718.

Casolaro, M., Anselmi, C., \& Picciocchi, G. (2005). The protonation thermodynamics of ferulic acid $/ \gamma$ cyclodextrin inclusion compounds. Thermochimica Acta, 425(1-2), 143-147.

Di Donato, C., Lavorgna, M., Fattorusso, R., Isernia, C., Isidori, M., Malgieri, G., ... Iacovino, R. (2016). Alpha- and beta-cyclodextrin inclusion complexes with 5-fluorouracil: Characterization and cytotoxic activity evaluation. Molecules, 21(12).

Ghosh, S., Basak, P., Dutta, S., Chowdhury, S., \& Sil, P. C. (2017). New insights into the ameliorative effects of ferulic acid in pathophysiological conditions. Food and Chemical Toxicology, 103, 41-55.

Gunn, J., \& Zhang, M. (2010). Polyblend nanofibers for biomedical applications: Perspectives and challenges. Trends in Biotechnology, 28(4), 189-197.

Hu, X., Liu, S., Zhou, G., Huang, Y., Xie, Z., \& Jing, $X$. (2014). Electrospinning of polymeric nanofibers for drug delivery applications. Journal of Controlled Release, 185(1), 12-21.

Huang, C., Chen, S., Lai, C., Reneker, D. H., Qiu, H., Ye, Y., \& Hou, H. (2006). Electrospun polymer nanofibres with small diameters. Nanotechnology, 17(6), 15581563.

Illangakoon, U. E., Yu, D. G., Ahmad, B. S., Chatterton, N. P., \& Williams, G. R. (2015). 5-Fluorouracil loaded Eudragit fibers prepared by electrospinning. International Journal of Pharmaceutics, 495(2), 895902.

Inokuchi, Reina; Takaichi, H; Kawano, T. (2016). Fluorometric Quantification of Ferulic Acid Concentrations Based on Deconvolution of Intrinsic Fluorescence Spectra. Environmental Materials in Biology, 54(1), 57-64.

Jin, M., Yu, D. G., Wang, X., Geraldes, C. F. G. C., Williams, G. R., \& Bligh, S. W. A. (2016). Electrospun Contrast-Agent-Loaded Fibers for Colon-Targeted MRI. Advanced Healthcare Materials, 5(8), 977-985. 
Krstic, M., Radojevic, M., Stojanovic, D., Radojevic, V., Uskokovic, P., \& Ibric, S. (2017). Formulation and characterization of nanofibers and films with carvedilol prepared by electrospinning and solution casting method. European Journal of Pharmaceutical Sciences. 101, 160-166.

Mancuso, C., \& Santangelo, R. (2014). Ferulic acid: Pharmacological and toxicological aspects. Food and Chemical Toxicology, 65, 185-195.

Mithu, S. H., Haque, S. N., Chowdhry, B. Z., Nokhodchi, A., \& Maniruzzaman, M. (2017). Evaluation of the surface chemistry and drug-polymer interaction of semi-crystalline micro-particles for the development of controlled release formulations. Materials Science \& Engineering C, 76, 559-567.

Pandey, K., Dwivedi, M. M., \& Tripathi, M. (2009). Structure, Interaction and Thermal Study in Electrolyte of Polyethylene Oxide/Silica/Ammonium Thiocynate Nanocomposites. Polymer Composites, 503-509.

Roy, N., Narayanankutty, A., Nazeem, P., Valsalan, R., Babu, T., \& Mathew, D. (2016). Plant phenolics ferulic acid and P-coumaric acid inhibit colorectal cancer cell proliferation through EGFR down- regulation. Asian Pacific Journal of Cancer Prevention, 17(8), 4017-4021.

Samprasit, W., Akkaramongkolporn, P., \& Ngawhirunpat, T. (2015). Fast releasing oral electrospun PVP / CD nano fiber mats of taste-masked meloxicam. International Journal of Pharmaceutics, 487(1-2), 213-222.

Shen, X., Yu, D., Zhu, L., Branford-White, C., White, K., \& Chatterton, N. P. (2011). Electrospun diclofenac sodium loaded Eudragit ${ }^{\circledR}$ L 100-55 nanofibers for colon-targeted drug delivery. International Journal of Pharmaceutics, 408(1-2), 200-207.

Son, Y. J., Kim, W. J., \& Yoo, H. S. (2014). Therapeutic applications of electrospun nanofibers for drug delivery systems. Archives of Pharmacal Research, 37(1), 69-78.

Topuz, F., \& Uyar, T. (2019). Electrospinning of cyclodextrin functional nanofibers for drug delivery applications. Pharmaceutics, 11(1).
Vashisth, P., Kumar, N., Sharma, M., \& Pruthi, V. (2015). Biomedical applications of ferulic acid encapsulated electrospun nanofibers. Biotechnology Reports, 8, 3644.

Wang, J., Cao, Y., Sun, B., \& Wang, C. (2011). Characterisation of inclusion complex of transferulic acid and hydroxypropyl- $\beta$-cyclodextrin. Food Chemistry, 124(3), 1069-1075.

Wang, L.-L., Zheng, W.-S., Chen, S.-H., Han, Y.X., \& Jiang, J.-D. (2016). Development of rectal delivered thermo-reversible gelling film encapsulating a 5-fluorouracil hydroxypropyl- $\beta$-cyclodextrin complex. Carbohydrate Polymers, 137, 9-18.

Wang, X., Yu, D. G., Li, X. Y., Bligh, S. W.A., \& Williams, G. R. (2015). Electrospun medicated shellac nanofibers for colon-targeted drug delivery. International Journal of Pharmaceutics, 490(1-2), 384-390.

Yang, J. M., Zha, L. sheng, Yu, D. G., \& Liu, J. (2013). Coaxial electrospinning with acetic acid for preparing ferulic acid/zein composite fibers with improved drug release profiles. Colloids and Surfaces B: Biointerfaces, 102, 737-743.

Zamani, M., Prabhakaran, M. P., \& Ramakrishna, S. (2013). Advances in drug delivery via electrospun and electrosprayed nanomaterials. International Journal of Nanomedicine, 8, 2997-3017.

Zhang, J., Wang, X., Liu, T., Liu, S., \& Jing, X. (2016). Antitumor activity of electrospun polylactide nanofibers loaded with 5-fluorouracil and oxaliplatin against colorectal cancer. Drug Delivery, 23(3), 794-800.

Zidane, S., Maiza, A., Bouleghlem, H., Herizi, W., \& Dahmani, S. (2016). Investigation of Cyclodextrin Inclusion Compounds Using FT-IR, SEM and X-Ray Diffraction. International Journal of Chemical Engineering and Applications, 7(3), 182-185. 